\title{
Bcl-2-like Protein 11 (BIM) Expression Is Associated with Favorable Prognosis for Patients with Cervical Cancer
}

\author{
BO WOOK KIM ${ }^{1,2}$, HANBYOUL CHO ${ }^{3}$, KRIS YLAYA ${ }^{1}$, HARUHISA KITANO ${ }^{1,4}$, \\ JOON-YONG CHUNG ${ }^{1}$, STEPHEN M. HEWITT ${ }^{1}$ and JAE-HOON KIM ${ }^{3}$ \\ ${ }^{1}$ Experimental Pathology Laboratory, Center for Cancer Research, \\ National Cancer Institute, National Institutes of Health, Bethesda, MD, U.S.A.; \\ ${ }^{2}$ Department of Obstetrics and Gynecology, International St. Mary's Hospital, \\ Catholic Kwandong University, Incheon, Republic of Korea; \\ ${ }^{3}$ Department of Obstetrics and Gynecology, Gangnam Severance Hospital, \\ College of Medicine, Yonsei University, Seoul, Republic of Korea; \\ ${ }^{4}$ Department of Thoracic Surgery, Shiga University of Medical Science, Otsu, Japan
}

\begin{abstract}
Background/Aim: Bcl-2-like protein 11 (BIM) is a pro-apoptotic member of the Bcl-2 protein family. BIM elicits cell death by binding to pro-survival Bcl-2 proteins. Even though the association of BIM expression with cell death has been investigated, its clinical survival significance in cervical cancer has not. In the current study, the prognostic significance of BIM in cervical cancer was investigated. Patients and Methods: The study included normal cervical tissues $(n=254)$, cervical intraepithelial neoplasia (CIN) tissues $(n=275)$, and invasive cervical cancer $(n=164)$. In order to identify BIM expression, immunohistochemistry (IHC) was performed, and IHC scoring by quantitative digital image analysis was determined. Then, the association of BIM with prognostic factors was investigated. Results: BIM expression was higher in cervical cancer than normal cervical tissues $(p<0.001)$. Well and moderate differentiation indicated higher BIM expression than did poor differentiation $(p=0.001)$. Also, BIM expression was high in radiation-sensitive cervical cancer relative to radiation-resistant cancer $(p=0.049)$. High BIM expression showed better 5-year disease-free survival
\end{abstract}

Correspondence to: Dr. Stephen M. Hewitt, Laboratory of Pathology, Center for Cancer Research, National Cancer Institute, National Institutes of Health, MSC1500, Bethesda, MD 20892 1500, U.S.A. Tel: +1 2407607171, Fax: +1 2405414470, e-mail: genejock@helix.nih.gov and Prof. Jae-Hoon Kim, Department of Obstetrics and Gynecology, Gangnam Severance Hospital, Yonsei University College of Medicine, 146-92 Dogok-Dong, GangnamGu, Seoul, 135-720, Republic of Korea. Tel: +82 220193436, Fax: +82 234628209, e-mail: jaehoonkim@yuhs.ac

Key Words: Bcl-2-like protein 11, cervical cancer, immunohistochemistry, survival rate.
(DFS) and overall survival (OS) rates ( $p=0.049$ and $\pi=0.030$, respectively) than did low expression. In a multivariate analysis, BIM was shown to be an independent risk factor for DFS and OS in cervical cancer, with hazard ratios of $0.22(p=0.006)$ and $0.46(p=0.046)$, respectively. Conclusion: BIM is associated with favorable prognostic markers for prediction of DFS and OS in cervical cancer. High BIM expression is a potential prognostic marker as well as a chemotherapeutic target for cervical cancer.

Cervical cancer is the fourth most common malignancy in women worldwide as well as a leading cause of women's death (1). Cervical cancer can be diagnosed early thanks to effective screening systems and the appearance of symptoms at its early stages, though advanced cases requiring multimodal treatment including chemotherapy, radiation and radical surgery still arise. Chemo-radiation therapy has produced favorable responses in patients with advanced cervical cancer; however, for some cervical cancer cells, specifically those that acquire resistance to chemo-radiation, treatment outcomes are unsatisfactory, patient death being the all-too-common result.

Resistance to chemo-radiation therapy is one of the major obstacles compromising advanced cervical cancer treatment, and its molecular mechanism is still not fully understood. Several sub-mechanisms have been proposed, including the presence of tumor hypoxia, mutations of genes involved in DNA repair, activation of intracellular signaling pathways, or cell-cycle regulation (2-5). In addition, the inability to induce apoptosis in cancer cells is one of the mechanisms of chemo-radiation resistance. On the other hand, an intact posttreatment apoptosis capacity in cancer cells might be a marker of chemo-radiation sensitivity and, thus, favorable treatment outcomes. 
Bcl-2-like protein 11 (BIM) is a $\mathrm{BH} 3$-only protein belonging to the Bcl-2 family that is involved in pro-survival and pro-apoptosis. BIM, a key regulator of pro-apoptosis, is released from the cytoskeleton after activation by cytotoxic signaling, and is then translocated to the mitochondria, where it results in apoptosis (6). The association between BIM and carcinogenesis has been investigated in several cancer cell types. In one study, loss of apoptotic function was observed in the case of BIM inactivation of even a single allele, resulting in accelerated growth of leukemia cells (7). BIM suppression by aberrant methylation or miRNAs decreases the apoptotic response and can contribute to therapeutic resistance in leukemia and lymphoma (8-10). BIM expression, by contrast, has been posited as predicting apoptotic responses as well as improving survival outcome; and in fact, up-regulation of BIM can restore cancer cells sensitive to targeted therapies in cases of non-small-cell lung cancer (NSCLC) (11).

In light of all of the cumulative evidences, it is suggested that down-regulation of BIM initiates tumorigenesis and that restoration of BIM function is one of the therapeutic targets in cancer treatment. However, data on the clinical relevance and molecular mechanism of BIM expression in cervical cancer remain limited. In the present study, having examined the clinical significance of BIM expression using a combination of immunohistochemistry (IHC) with quantitative image analysis, we were able to demonstrate that BIM expression is an independent prognostic factor in patients with cervical cancer.

\section{Patients and Methods}

Patient selection. The study included 439 patients who had been diagnosed as cervical intraepithelial neoplasia (CIN, n=275) and cervical cancer $(n=164)$ as well as 254 matched non-adjacent normal cervices between 1996 and 2010 at Gangnam Severance Hospital, Yonsei University College of Medicine in Seoul, Republic of Korea. Some of the paraffin blocks were provided by the Korea Gynecologic Cancer Bank through the Bio \& Medical Technology Development Program of the Ministry of Education, Science and Technology, Korea (NRF-2012M3A9B8021800). The patients' data including age, cancer stage, tumor differentiation, cell type, tumor size, lymphovascular invasion, lymph node (LN) metastasis and radiation therapy were collected. The tumor stage was determined based on the International Federation of Gynecology and Obstetrics (FIGO) scale and was histologically classified and graded according on the World Health Organization (WHO) grade. Patients with operability indications underwent radical hysterectomy with pelvic and aortic LN dissection; in certain cases, concurrent chemoradiation therapy was added depending on risk factors such as $\mathrm{LN}$ metastasis, parametrial invasion and positive resection margin. Patients with inoperability indications received either radiation or chemo-radiation therapy. Radiation resistance was designated as "recurrence" within 3 years after radiation or chemo-radiation therapy, while radiation sensitivity was designated as "no recurrence" within 3 years after radiation or chemo-radiation therapy $(12,13)$. This study was approved by the Institutional
Review Board (IRB \#3-2010-0030; Seoul, Korea) of Gangnam Severance Hospital. It was additionally approved by the Office of Human Subjects Research at the National Institutes of Health (Bethesda, MD, USA).

Tissue microarray construction and immunohistochemistry. Tissue microarrays (TMAs) were prepared from 439 formalin-fixed paraffin-embedded tissue specimens, and 254 normal (non-adjacent to tumor) samples. All of the slides were reviewed by a pathologist. Areas containing each category were indicated on the hematoxylin $\&$ eosin (H\&E) slides by marking them with a dotting pen. Four tissue cores of $1.0 \mathrm{~mm}$ diameter were then taken from the corresponding regions of the paraffin blocks and transplanted into a recipient paraffin block using a tissue arrayer (Pathology Devices, Westminster, MD, USA). For immunohistochemical staining, all of the paraffin-embedded sections were cut to 5 micron thickness, deparaffinized through xylene and dehydrated with graded ethanols. Antigen recovery was performed in heat-activated antigen retrieval pH 9 (Dako, Carpinteria, CA, USA) for BIM, after which the specimens were incubated with $3 \% \mathrm{H}_{2} \mathrm{O}_{2}$ for $15 \mathrm{~min}$. Non-specific binding was blocked with protein block (Dako) for $20 \mathrm{~min}$ at room temperature. The TMA sections were incubated with anti-BIM rabbit monoclonal antibodies (clone no. C34C5; Cell Signaling, Denver, MA, USA) at 1:50 dilution for $2 \mathrm{~h}$. Subsequently, the sections were incubated with EnVision ${ }^{+}$Dual Link System-HRP (Dako) for $30 \mathrm{~min}$, visualized with 3,3-diaminobenzadine for $10 \mathrm{~min}$, and washed and counterstained with hematoxylin. Appropriate negative controls were concurrently performed, and the TMAs included appropriate positive-control tissues.

Digital image analysis. The immunohistochemically stained slides were digitized at $20 \times$ magnification utilizing an Aperio Scanscope CS (Aperio, Vista, CA, USA). The Aperio Scanscope CS acquires 20x images with a spatial resolution of $0.50 \mu \mathrm{m} /$ pixels. Images were reviewed utilizing an online software application, Digital Image Hub (SlidePath, Dublin, Ireland), which enables users to annotate normal and tumor regions. Once the areas were annotated, they were sent for automated image analysis utilizing TissueIA (SlidePath's Tissue IA system, version 3.0, Dublin, Ireland). Within Tissue IA, an algorithm developed to quantify cytoplasmic BIM was run as follows: BIM was stained in the cytoplasm; the algorithm output returns a number of quantitative measurements, namely the intensity, concentration and percentage of positive staining present. Subsequently, the quantitative intensity and percentage were categorized into 4 and 5 classes, respectively, after cut-off values were determined. The intensity of staining was categorized as 0 (no staining), $1+$ (weak), 2+ (moderate) and $3+$ (strong); the percentage of staining was categorized as 0 $(\leq 5 \%), 1+(6-25 \%), 2+(26-50 \%), 3+(51-75 \%)$ and $4+(\geq 75 \%)$. The final IHC score was calculated based on the combination of the intensity and percentage scores (range $=0-12)(14,15)$.

Statistical analysis. The IHC scores were compared using the oneway ANOVA and independent $t$-tests. The immunohistochemical cut-off for high expression of BIM was calculated by receiver operating characteristic (ROC) curve analysis. For each IHC score, the sensitivity (1-specificity) for discrimination of death or survival was determined and plotted, thus generating the ROC curve. The cut-off value was established to be the point on the curve where the sum of sensitivity and specificity was maximized (16). A Kaplan-Meier survival analysis was performed to determine the 
Table I. Clinicopathological characteristics.

\begin{tabular}{|c|c|c|}
\hline & Frequency & $\%$ \\
\hline Age & $43.0^{\mathrm{a}}$ & \\
\hline \multicolumn{3}{|l|}{ Diagnostic category } \\
\hline Normal & 254 & 36.6 \\
\hline CIN & 275 & 39.7 \\
\hline Cervical cancer & 164 & 23.7 \\
\hline \multicolumn{3}{|l|}{ FIGO stage } \\
\hline I & 111 & 67.7 \\
\hline II & 47 & 28.7 \\
\hline IV & 6 & 3.6 \\
\hline \multicolumn{3}{|l|}{ Tumor differentiation } \\
\hline Well to Moderate & 96 & 60.8 \\
\hline Poor & 62 & 39.2 \\
\hline \multicolumn{3}{|l|}{ Cell type } \\
\hline Squamous cell carcinoma & 137 & 83.5 \\
\hline Adenocarcinoma & 14 & 8.5 \\
\hline Others & 13 & 8 \\
\hline \multicolumn{3}{|l|}{ Tumor size } \\
\hline$\leq 4 \mathrm{~cm}$ & 115 & 70.1 \\
\hline$>4 \mathrm{~cm}$ & 49 & 29.9 \\
\hline \multicolumn{3}{|l|}{ Lymphovascular invasion ${ }^{b}$} \\
\hline No & 81 & 55.1 \\
\hline Yes & 66 & 44.9 \\
\hline \multicolumn{3}{|l|}{ Lymph node (LN) metastasisc } \\
\hline No & 111 & 74.5 \\
\hline Yes & 38 & 25.5 \\
\hline
\end{tabular}

CIN: Cervical intraepithelial neoplasia; FIGO: International Federation of Gynecology and Obstetrics. ${ }^{\mathrm{M} M e a n}$ value; ${ }^{\mathrm{b}}$ calculated only 147 cases with available information on examined lymphovascular invasion; ${ }^{c}$ calculated only 149 cases with available information on examined LN.

association of BIM with disease-free survival (DFS) and overall survival (OS), and the survival curves were compared between the groups using log-rank tests. Multivariate analyses of the hazard ratios for recurrence and death were performed using Cox proportional hazards regression. Statistical analyses were performed using SPSS version 19.0 (SPSS Inc., Chicago, IL, USA). A value of $p<0.05$ was considered statistically significant.

\section{Results}

Clinicopathological characteristics of patients. The patient's clinicopathologica characteristics are summarized in Table I. Their ages ranged from $19-83$ years (mean $=43.0$ years). The cervical tumor samples included $275 \mathrm{CIN}$ and 164 cervical cancer tissues. Among the 164 cervical cancer samples, 111 were FIGO stage I, 47 stage II, and 6 stage IV. The tumor sizes ranged from $0.2-12 \mathrm{~cm}$ (mean=2.8 cm). The cancer cell types included 137 squamous cell carcinoma (SCC), 14 adenocarcinomas, 7 adenosquamous and 6 other types (2 small-cell carcinoma, 2 neuroendocrine, and 2 mixed cell types). Fifty-two patients received radiation or chemoradiation therapy, 16 of whom $(30.8 \%)$ suffered recurrence.
Table II. Association of BIM mean IHC scores with clinicopathological characteristics.

\begin{tabular}{|c|c|c|c|}
\hline & $\mathrm{N}$ & $\begin{array}{c}\text { Mean IHC score } \\
\quad(95 \% \mathrm{CI})\end{array}$ & $p$-Value \\
\hline Diagnostic category & & & $<0.001$ \\
\hline Normal & 254 & $0.24(0.17-0.32)$ & \\
\hline CIN I & 59 & $0.64(0.39-0.89)$ & \\
\hline CIN II and III & 216 & $3.32(2.91-3.74)$ & \\
\hline Cervical cancer & 164 & $2.65(2.25-3.05)$ & \\
\hline FIGO stage & & & 0.041 \\
\hline I & 111 & $2.34(1.88-2.80)$ & \\
\hline II & 47 & $3.15(2.36-3.94)$ & \\
\hline IV & 6 & $4.50(0.64-8.36)$ & \\
\hline Tumor differentiation & & & 0.001 \\
\hline Well + Moderate & 96 & $3.06(2.50-3.62)$ & \\
\hline Poor & 62 & $1.74(1.24-2.24)$ & \\
\hline Cell Type & & & 0.008 \\
\hline Squamous cell carcinoma & 137 & $2.89(2.46-3.32)$ & \\
\hline Others & 27 & $1.44(0.44-2.45)$ & \\
\hline Tumor size & & & 0.742 \\
\hline$<4 \mathrm{~cm}$ & 115 & $2.61(2.12-3.10)$ & \\
\hline$\geq 4 \mathrm{~cm}$ & 49 & $2.76(2.04-3.47)$ & \\
\hline Lymphovascular invasion & & & 0.554 \\
\hline Negative & 81 & $2.56(2.03-3.08)$ & \\
\hline Positive & 66 & $2.32(1.71-2.93)$ & \\
\hline Lymph node (LN) metastasis & & & 0.213 \\
\hline Negative & 111 & $2.31(1.91-2.70)$ & \\
\hline Positive & 38 & $2.87(1.84-3.89)$ & \\
\hline Radiation sensitivity & & & 0.049 \\
\hline Sensitive & 36 & $3.06(2.01-4.10)$ & \\
\hline Resistant & 16 & $1.75(0.91-2.59)$ & \\
\hline
\end{tabular}

CIN: Cervical intraepithelial neoplasia; FIGO: International Federation of Gynecology and Obstetrics; CI: confidence interval.

A survival analysis of the 164 cervical cancers indicated that the mean follow-up time of the survival patients was 58.2 months (range=1-179 months). Fifty patients (9.1\%) deceased during the follow-up period.

BIM expression. Expression of BIM was evaluated by IHC analysis of cervical tumors. Subsequently, the cancer specimens and IHC scores were analyzed using digital image software. The representative BIM IHC expression is shown in Figure 1. BIM expression was clearly observed in the cytoplasm. Sixty $(36.6 \%)$ of the 164 cervical cancer tissues presented high expression of BIM, as did $97(35.3 \%)$ of the 275 CINs. The clinical significances of BIM expression in cervical cancer are presented in Table II. BIM expression was significantly higher in high-grade CIN and cervical cancer than in normal or low-grade CIN lesions $(p<0.001)$. BIM expression was significantly correlated with FIGO stage, well and moderate tumor differentiation, and the squamous cell carcinoma cell type ( $p=0.041,0.001$, and 0.008 , respectively). 

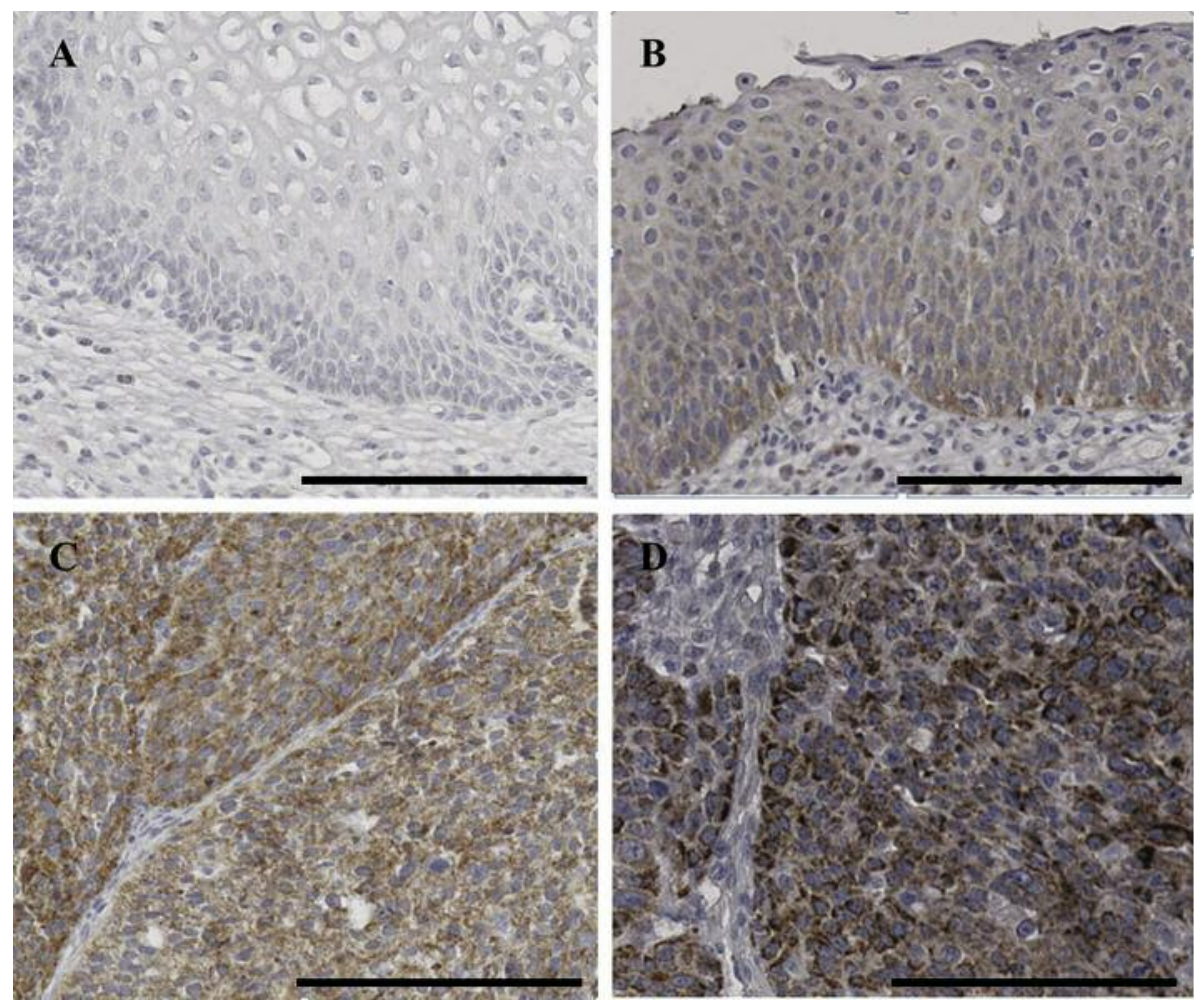

Figure 1. Representative immunohistochemical staining for cytoplasmic BIM in cervical tissues: (A) no staining in normal cervix, (B) weak staining intensity in cervical intraepithelial lesion, $(C)$ moderate staining intensity in squamous cell carcinoma and (D) strong intensity in squamous cell carcinoma. Scale bar: $100 \mu \mathrm{m}$.

A

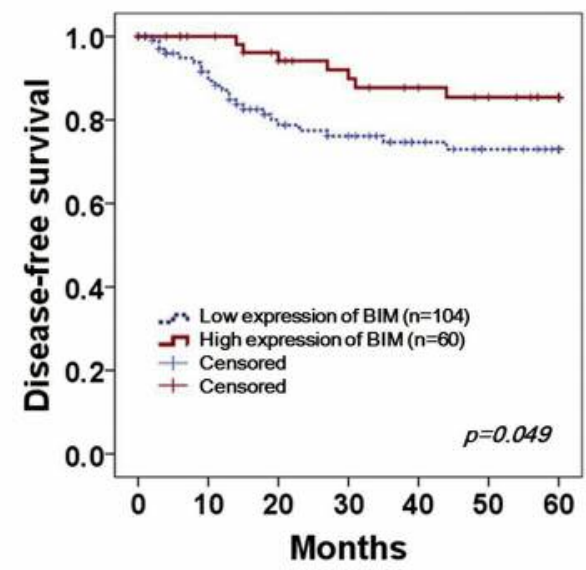

B

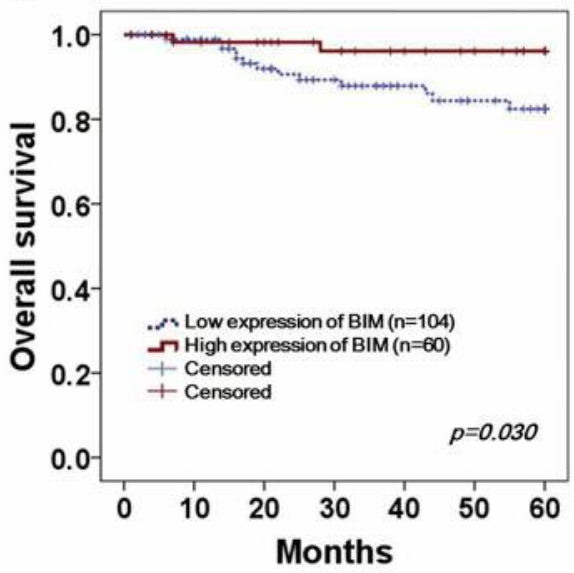

Figure 2. Kaplan-Meier survival curves of BIM expression in cervical cancer. Cervical cancer patients with high BIM expression present (A) better 5 -year DFS and (B) OS ( $p=0.049$ and $p=0.030$, respectively) than those with low BIM expression.

High expression of BIM, meanwhile, was correlated with chemo-radiation sensitivity $(p=0.049)$. However, there was no association between BIM expression and tumor size, lymphovascular space invasion or LN metastasis.
Survival significance of BIM. The five-year DFS and OS were analyzed by Kaplan-Meier plot, as shown in Figure 2 . According to the results, 7 recurrences (11.6\%) and 2 deaths (3.3\%) occurred in 60 cases of high BIM expression, 
Table III. Multivariate survival analysis of DFS and OS.

\begin{tabular}{lccccc}
\hline & \multicolumn{2}{c}{ DFS } & & OS \\
\cline { 2 - 3 } & Hazard ratio [95\%CI] & $p$-Value & & Hazard ratio [95\%CI] & $p$-Value \\
\hline FIGO stage ( $\geq$ IIB) & $3.67[1.54-8.75]$ & 0.003 & $1.92[0.56-6.59]$ & 0.298 \\
Tumor size $(>4 \mathrm{~cm})$ & $0.78[0.34-1.80]$ & 0.567 & & $1.01[0.31-3.22]$ & 0.982 \\
LN metastasis (positive) & $5.26[2.08-13.27]$ & 0.001 & & $0.08[1.67-22.10]$ & 0.006 \\
BIM (high expression) & $0.22[0.07-0.65]$ & 0.006 & $0.46[0.01-0.96]$ & 0.046 \\
\hline
\end{tabular}

FIGO: International Federation of Gynecology and Obstetrics; LN: lymph nodes.

whereas 23 recurrences $(22.1 \%)$ and 13 deaths (12.5\%) were observed in 104 cases of low BIM expression. The highexpression BIM group had a better DFS rate than did the low-expression group $(p=0.049)$ (Figure 2A). High expression of BIM, furthermore, was also associated with an improved OS rate compared to low expression and the difference was statistically significant $(p=0.030)$ (Figure $2 \mathrm{~B}$ ).

Next, a Cox proportional multivariate analysis was performed to evaluate the correlation of BIM with DFS and OS outcomes (Table III). In the DFS analysis, FIGO stage, $\mathrm{LN}$ metastasis and BIM expression were determined to be independent survival factors. High expression of BIM showed a 0.22 hazard ratio for DFS, with statistical significance $(p=0.006)$. In the OS analysis, LN metastasis and BIM expression emerged as the independent survival factors. The hazard ratio for high expression of BIM was 0.46 for OS, with statistical significance $(p=0.046)$.

\section{Discussion}

Apoptotic inability can be an inducement to tumorigenesis and a hindrance to resistance, eventually leading to poor patient survival outcome. BIM is a key modulator of apoptosis; loss of BIM expression, therefore, can cause both tumor progression and resistance to chemo-radiation therapy. In the current study, we assessed, by IHC, the clinical correlations and prognostic significances of BIM expression in cervical cancer. We found that BIM was highly expressed in high-grade CIN and cervical cancer relative to normal cervix and low-grade CIN. Loss of BIM expression was associated with aggressive tumor phenotypes, while high BIM expression correlated highly with prolonged DFS and OS. Notably, BIM also was shown to be an independent prognostic factor for DFS and OS. Overall, our results suggested that BIM is a potential clinical prognostic factor for cervical cancer.

The Bcl-2 family is comprised of anti-apoptotic members such as Bcl-2, Bcl-xL and Mcl-1 as well as pro-apoptotic members including the Bcl-2-homology domain 3 only (BH3only) proteins. BIM belongs to $\mathrm{BH} 3$-only family of proteins, and is known to be essential for initiation of apoptosis. BIM is regulated by transcriptional and post-transcriptional stimuli. Transcriptional regulators such as forkhead box $\mathrm{O} 3 \mathrm{a}$ (FOXO3a) and runt-related protein3 (Runx3) are involved in BIM up-regulation (17-19). Up-regulation of BIM activates the pro-apoptotic protein of the Bcl-2 antagonist or killer (BAK) and Bcl-2-associated $\mathrm{X}$ protein (BAX), resulting in the release of cytochrome $\mathrm{c}$ from the mitochondria (20). On the other hand, activation of the EGFR-ERK pathway downregulates BIM through proteasomal degradation of BIM after ubiquitination of phosphorylated BIM (21). EGFR mutations initiate MEK/ERK activation of the pro-survival pathway, which signaling inhibits BIM activation (22). By contrast, inhibition of the MEK/ERK pathway restores BIM expression, resulting in induction of apoptosis in EGFRmutant NSCLC (22-24). In EGFR-mutant lung cancer, EGFR tyrosine kinase inhibitors such as erlotinib and gefitinib effectively inhibit EGFR signaling, and so BIM up-regulation through EGFR inhibition is one of the important targets for tumor apoptosis $(23,25)$. According to a recent report, EGFR mutation was observed in $32.6 \%$ of cervical cancer cases, and EGFR inhibition was effective in cell lines with EGFR mutations (26). Considering all of the above-noted results, BIM can be considered to be an important therapeutic target for EGFR-inhibition therapy; indeed, our favorable survival data for high BIM expression is evidence for application of EGFR inhibition to the treatment of EGFR-mutant cervical cancer.

Radiation sensitivity and survival significance for the Bcl2 family members has been investigated for cases of cervical cancer. The Bcl-2 family is comprised of two groups: prosurvival members including $\mathrm{Bcl}-2$ and $\mathrm{Bcl}-\mathrm{xL}$, and proapoptotic members such as BAD, BAX and BIM. Mukherjee et al. performed a pathologic analysis of Bcl-2 and BAX proteins in a comparison of radiation-sensitive with radiation-resistant tissue samples (27). Expression of Bcl-2 and pro-survival factors showed radiation resistance in $15 \%$ of cases, whereas radiation-sensitive tumors did not present Bcl-2 staining. By contrast, BAX, among the pro-apoptotic factors, showed high expression in radio-sensitive and low 
expression in radio-resistant tumors (27). Whereas Bcl-2 and $\mathrm{BAX}$ have been investigated for responsiveness to radiation therapy, BIM's clinical significance to radiation sensitivity and survival outcomes has not. To our knowledge, this current report is the first to show that high expression of BIM is correlated with radiation sensitivity and, thus, offers a survival benefit to cervical cancer patients.

BIM's significance to survival has been investigated for other cancers. Two reports for example, citing survival data similar to ours, indicated that BIM mRNA expression is correlated with prolonged survival in EGFR-mutant NSCLC $(11,28)$. In the latter report moreover, a correlation of BIM with increased sensitivity to erlotinib and chemotherapy, which resulted in prolonged survival, was posited (28). Modulation of BIM stability by pyruvate kinase M2 has decreased apoptosis and showed a poor survival outcome for hepatocellular carcinoma. In cutaneous melanoma, BIM expression has been revealed to be in inverse correlation with adverse prognostic factors such as tumor thickness, metastasis and cancer stage; in one study's univariate analysis, BIM trended to improved OS outcome, though the subsequent multivariate analysis showed no such association (29). In the current study, low expression of BIM was associated with poor tumor differentiation, radiation resistance and, thus, poor OS. Certainly, in light of both the previously reported data and our present results, low BIM expression can be considered to be associated with adverse prognostic factors and poor survival.

Although our pathologic and survival data related to BIM expression included a relatively large number of cases, the significance of BIM to radiation sensitivity is not conclusive, given the limited number of patients who actually received radiation. The exact role that BIM plays in radiation sensitivity and its potential as an important therapeutic target in cervical cancer treatment require further investigation.

In conclusion, BIM showed high expression in cases of well and moderate tumor differentiation and radiation sensitivity. BIM also was associated with improved DFS and OS in cervical cancer.

\section{Acknowledgements}

This work was supported in part by the Intramural Research Program of the National Institutes of Health (NIH), the National Cancer Institute, the Center for Cancer Research, and grants from the Basic Science Research Program through the National Research Foundation of Korea (NRF) funded by the Ministry of Education, Science and Technology (2011-0005230, 2011-0010286 and 20110007146).

\section{References}

1 Torre LA, Bray F, Siegel RL, Ferlay J, Lortet-Tieulent J and Jemal A: Global cancer statistics, 2012. CA Cancer J Clin 65(2): $87-108,2015$.
2 Fu Z, Chen D, Cheng H and Wang F: Hypoxia-inducible factor1alpha protects cervical carcinoma cells from apoptosis induced by radiation via modulation of vascular endothelial growth factor and p53 under hypoxia. Med Sci Monit 21: 318-325, 2015.

3 Shibata A and Jeggo PA: DNA double-strand break repair in a cellular context. Clin Oncol (R Coll Radiol) 26(5): 243-249, 2014.

4 Skvortsov S, Debbage P, Lukas P and Skvortsova I: Crosstalk between DNA repair and cancer stem cell (csc) associated intracellular pathways. Semin Cancer Biol 31: 36-42, 2015.

5 Pawlik TM and Keyomarsi K: Role of cell cycle in mediating sensitivity to radiotherapy. Int J Radiat Oncol Biol Phys 59(4): 928-942, 2004.

6 Lei $\mathrm{K}$ and Davis RJ: Jnk phosphorylation of bim-related members of the bc12 family induces bax-dependent apoptosis. Proc Natl Acad Sci USA 100(5): 2432-2437, 2003.

7 Egle A, Harris AW, Bouillet P and Cory S: Bim is a suppressor of myc-induced mouse b cell leukemia. Proc Natl Acad Sci USA 101(16): 6164-6169, 2004.

8 Richter-Larrea JA, Robles EF, Fresquet V, Beltran E, Rullan AJ, Agirre X, Calasanz MJ, Panizo C, Richter JA, Hernandez JM, Roman-Gomez J, Prosper F and Martinez-Climent JA: Reversion of epigenetically mediated bim silencing overcomes chemoresistance in burkitt lymphoma. Blood 116(14): 25312542, 2010.

9 San Jose-Eneriz E, Agirre X, Jimenez-Velasco A, Cordeu L, Martin V, Arqueros V, Garate L, Fresquet V, Cervantes F, Martinez-Climent JA, Heiniger A, Torres A, Prosper F and Roman-Gomez J: Epigenetic down-regulation of bim expression is associated with reduced optimal responses to imatinib treatment in chronic myeloid leukaemia. Eur J Cancer 45(10): 1877-1889, 2009.

10 Xiao C, Srinivasan L, Calado DP, Patterson HC, Zhang B, Wang J, Henderson JM, Kutok JL and Rajewsky K: Lymphoproliferative disease and autoimmunity in mice with increased mir-17-92 expression in lymphocytes. Nat Immunol 9(4): 405414, 2008.

11 Faber AC, Corcoran RB, Ebi H, Sequist LV, Waltman BA, Chung E, Incio J, Digumarthy SR, Pollack SF, Song Y, Muzikansky A, Lifshits E, Roberge S, Coffman EJ, Benes CH, Gomez HL, Baselga J, Arteaga CL, Rivera MN, Dias-Santagata D, Jain RK and Engelman JA: Bim expression in treatmentnaive cancers predicts responsiveness to kinase inhibitors. Cancer Discov 1(4): 352-365, 2011.

12 Huang X, Liu M, Sun H, Wang F, Xie X, Chen X, Su J, He Y, Dai $\mathrm{Y}, \mathrm{Wu} \mathrm{H}$ and Shen L: Hk2 is a radiation resistant and independent negative prognostic factor for patients with locally advanced cervical squamous cell carcinoma. Int J Clin Exp Pathol 8(4): 4054-4063, 2015.

13 Kim TJ, Lee JW, Song SY, Choi JJ, Choi CH, Kim BG, Lee JH and Bae DS: Increased expression of pakt is associated with radiation resistance in cervical cancer. Br J Cancer 94(11): 16781682, 2006.

14 Koo CL, Kok LF, Lee MY, Wu TS, Cheng YW, Hsu JD, Ruan A, Chao KC and Han CP: Scoring mechanisms of p16ink4a immunohistochemistry based on either independent nucleic stain or mixed cytoplasmic with nucleic expression can significantly signal to distinguish between endocervical and endometrial adenocarcinomas in a tissue microarray study. $\mathrm{J}$ Transl Med 7: 25, 2009. 
15 Kim BW, Cho H, Chung JY, Conway C, Ylaya K, Kim JH and Hewitt SM: Prognostic assessment of hypoxia and metabolic markers in cervical cancer using automated digital image analysis of immunohistochemistry. J Transl Med 11: 185, 2013.

16 Zlobec I, Steele R, Terracciano L, Jass JR and Lugli A: Selecting immunohistochemical cut-off scores for novel biomarkers of progression and survival in colorectal cancer. J Clin Pathol 60(10): 1112-1116, 2007.

17 Barreyro FJ, Kobayashi S, Bronk SF, Werneburg NW, Malhi H and Gores GJ: Transcriptional regulation of bim by foxo3a mediates hepatocyte lipoapoptosis. J Biol Chem 282(37): 2714127154, 2007.

18 Sunters A, Fernandez de Mattos S, Stahl M, Brosens JJ, Zoumpoulidou G, Saunders CA, Coffer PJ, Medema RH, Coombes RC and Lam EW: Foxo3a transcriptional regulation of bim controls apoptosis in paclitaxel-treated breast cancer cell lines. J Biol Chem 278(50): 49795-49805, 2003.

19 Yano T, Ito K, Fukamachi H, Chi XZ, Wee HJ, Inoue K, Ida H, Bouillet P, Strasser A, Bae SC and Ito Y: The runx3 tumor suppressor upregulates bim in gastric epithelial cells undergoing transforming growth factor beta-induced apoptosis. Mol Cell Biol 26(12): 4474-4488, 2006.

20 Letai A, Bassik MC, Walensky LD, Sorcinelli MD, Weiler S and Korsmeyer SJ: Distinct bh3 domains either sensitize or activate mitochondrial apoptosis, serving as prototype cancer therapeutics. Cancer Cell 2(3): 183-192, 2002.

21 Reginato MJ, Mills KR, Paulus JK, Lynch DK, Sgroi DC, Debnath J, Muthuswamy SK and Brugge JS: Integrins and egfr coordinately regulate the pro-apoptotic protein bim to prevent anoikis. Nat Cell Biol 5(8): 733-740, 2003.

22 Cragg MS, Kuroda J, Puthalakath H, Huang DC and Strasser A: Gefitinib-induced killing of nsclc cell lines expressing mutant egfr requires bim and can be enhanced by bh3 mimetics. PLoS Med 4(10): 1681-1689, 2007.

23 Costa DB, Halmos B, Kumar A, Schumer ST, Huberman MS, Boggon TJ, Tenen DG and Kobayashi S: Bim mediates egfr tyrosine kinase inhibitor-induced apoptosis in lung cancers with oncogenic egfr mutations. PLoS Med 4(10): 1669-1679, 2007.

24 Deng J, Shimamura T, Perera S, Carlson NE, Cai D, Shapiro GI, Wong KK and Letai A: Proapoptotic bh3-only bcl-2 family protein bim connects death signaling from epidermal growth factor receptor inhibition to the mitochondrion. Cancer Res 67(24): 11867-11875, 2007.
25 Karachaliou N, Codony-Servat J, Teixido C, Pilotto S, Drozdowskyj A, Codony-Servat C, Gimenez-Capitan A, MolinaVila MA, Bertran-Alamillo J, Gervais R, Massuti B, Moran T, Majem M, Felip E, Carcereny E, Garcia-Campelo R, Viteri S, Gonzalez-Cao M, Morales-Espinosa D, Verlicchi A, Crisetti E, Chaib I, Santarpia M, Luis Ramirez J, Bosch-Barrera J, Felipe Cardona A, de Marinis F, Lopez-Vivanco G, Miguel Sanchez J, Vergnenegre A, Sanchez Hernandez JJ, Sperduti I, Bria E and Rosell R: Bim and mtor expression levels predict outcome to erlotinib in egfr-mutant non-small-cell lung cancer. Sci Rep 5: 17499, 2015.

26 Qureshi R, Arora H, Biswas S, Perwez A, Naseem A, Wajid S, Gandhi $G$ and Rizvi MA: Mutation analysis of egfr and its correlation with the hpv in indian cervical cancer patients. Tumour Biol 37(7): 9089-9098, 2016.

27 Mukherjee G, Freeman A, Moore R, Kumaraswamy, Devi KU, Morris LS, Coleman N, Dilworth S, Prabhakaran PS and Stanley MA: Biologic factors and response to radiotherapy in carcinoma of the cervix. Int J Gynecol Cancer 11(3): 187-193, 2001.

28 Costa C, Molina MA, Drozdowskyj A, Gimenez-Capitan A, Bertran-Alamillo J, Karachaliou N, Gervais R, Massuti B, Wei J, Moran T, Majem M, Felip E, Carcereny E, Garcia-Campelo $\mathrm{R}$, Viteri S, Taron M, Ono M, Giannikopoulos P, Bivona T and Rosell R: The impact of egfr $\mathrm{t} 790 \mathrm{~m}$ mutations and bim mrna expression on outcome in patients with egfr-mutant nsclc treated with erlotinib or chemotherapy in the randomized phase iii eurtac trial. Clin Cancer Res 20(7): 2001-2010, 2014.

29 Gambichler T, Rooms I, Scholl L, Stockfleth E, Stucker M and Sand M: Bh3-only protein bim predicts advanced stage of cutaneous melanoma. J Eur Acad Dermatol Venereol 30(11): 1926-1929, 2016.
Received July 13, 2017

Revised July 29, 2017

Accepted August 1, 2017 